\title{
Heterotrophy of filamentous oleaginous microalgae Tribonema minus for potential production of lipid and palmitoleic acid
}

\author{
Wenjun Zhou, Hui Wang, Lin Chen, Wentao Cheng, Tianzhong Liu* \\ Key Laboratory of Biofuels, Key Laboratory of Shandong Energy Biological Genetic Resources, Qingdao Institute of Bioenergy and Bioprocess Technology, Chinese Academy of \\ Sciences, Qingdao 266071, China
}

\section{H I G H L I G H T S}

- Heterotrophic ability of microalgae Tribonema minus was identified for the first time.

- Glucose and urea were the optimal sources for heterotrophic fermentation of T. minus.

- Highest biomass and lipid productivity of $30.8 \mathrm{~g} \mathrm{~L}^{-1}$ and $730 \mathrm{mg} \mathrm{L}^{-1} \mathrm{~d}^{-1}$ were obtained.

- The percentage of palmitoleic acid in fatty acid profile reached up to $50.1 \%$.

- Effects of nutrient, pH and temperature on T. minus heterotrophy were investigated.

\section{A R T I C L E I N F O}

\section{Article history:}

Received 14 April 2017

Received in revised form 7 May 2017

Accepted 8 May 2017

Available online 10 May 2017

\section{Keywords:}

Tribonema minus

Heterotrophic fermentation

Lipid

Palmitoleic acid

Cultivation optimization

\begin{abstract}
A B S T R A C T
Heterotrophic fermentation and high valuable co-product producing are thought to be effective ways to improve the economic viability and feasibility of commercial production of microalgae biofuels. This work reported the heterotrophic cultivation of Tribonema minus for lipid and palmitoleic acid (a novel functional fatty acid) production. Firstly, the heterotrophic ability of $T$. minus was identified for the first time with significant promotion in biomass and lipid productivity, and glucose and urea were then selected as the optimal carbon and nitrogen sources. Moreover, nutrient concentrations and culture conditions were optimized. Highest biomass and lipid productivity of $30.8 \mathrm{~g} \mathrm{~L}^{-1}$ and $730 \mathrm{mg} \mathrm{L}^{-1} \mathrm{~d}^{-1}$ were obtained respectively by adding $80 \mathrm{~g} \mathrm{~L}^{-1}$ glucose at once. In addition, $2 \mathrm{~g} \mathrm{~L}^{-1}$ urea, $0.8 \mathrm{~g} \mathrm{~L}^{-1} \mathrm{~K}_{2} \mathrm{HPO}_{4}$, $24 \mathrm{mg} \mathrm{L}^{-1}$ ammonium ferric citrate, initial $\mathrm{pH}$ of 6 , and temperature of $27^{\circ} \mathrm{C}$ were determined as the appropriate conditions for heterotrophic growth and lipid production.
\end{abstract}

(c) 2017 Elsevier Ltd. All rights reserved.

\section{Introduction}

The recent decade witnessed a bloomed interest in oleaginous microalgae as a promising sustainable source for biodiesel production associated with positive impacts on environmental mitigation. However, microalgae biofuel technology remains in its infancy. One of the most critical problems is the inefficiency and high cost of the production of microalgae biomass and lipid. Microalgae can grow with $\mathrm{CO}_{2}$ as the carbon source and sunlight as the energy supply. However, traditional photoautotrophic cultivation of microalgae is highly dependent on the climatic and seasonal conditions, and the long cultivation period, especially low biomass and lipid productivities damage the economic viability and the potential of commercial production (Wijffels and Barbosa, 2010). In comparison to photoautotrophic cultivation, heterotrophic fermentation allows

\footnotetext{
* Corresponding author.

E-mail address: liutz@qibebt.ac.cn (T. Liu).
}

microalgal cells to grow very fast, accumulate dense biomass and lipid oil within less time and the scale-up is much easier. Thus, it offers a potential pathway to produce oil for diesel production in large scale (Griffiths and Harrison, 2009; Rodolfi et al., 2009). Accumulating studies indicate that various species of microalgae can be cultured heterotrophically, however, there are only a few Chlorella sp. strains such as $C$. protothecoides, $C$. pyrenoidosa and $C$. vulgaris, and Crypthecodinium sp. strains such as $C$. cohnii demonstrated efficient fermentation capacity using organic carbon sources, especially glucose (de Swaaf et al., 2003; Xiong et al., 2008; Wei et al., 2009; Han et al., 2012; Xiao et al., 2015).

It has been suggested that microalgal strains producing valuable co-products, such as feed, pigments, chemicals or pharmaceuticals, would further improve the economic viability of microalgal biofuel production (Pienkos and Darzins, 2009; Brennan and Owende, 2010; Singh and Gu, 2010). To date, omega-3 fatty acid, eicosapentanoic acid, decosahexaenoic acid and chlorophyll have been shown to be potentially valuable co-products of microalgal 
biodiesel production (Spolaore et al., 2006; Becker, 2007; Harun et al., 2010). Palmitoleic acid (16:1), also called cis-9Hexadecenoic acid, which is belonged to omega-7 fatty acid, has been paid increasing interest as one of novel functional fatty acid. Palmitoleic acid is an important contributor to human health and sustainable industry, and it received increasing attention in recent years (Wu et al., 2012). Immense amounts of studies released recent years indicate that palmitoleic acid shows application values in increasing insulin sensitivity, increasing cell membrane fluidity, reducing inflammation, protecting cardiovascular system, and inhibiting oncogenesis (Stefan et al., 2010; Maedler et al., 2003; Mozaffarian et al., 2010; Welters et al., 2006). Currently, soft gels containing purified palmitoleic acid have been put into market as healthcare products (http://omega-7.org/). Moreover, palmitoleic acid is thought to be better to provide low temperature property than other saturated fatty acid when it was converted into biodiesel because of its carbon chain length and unsaturated double bond number (Knothe, 2010; Cao et al., 2014). Besides, palmitoleic acid could be used to produce 1-octene which is highly consumed in the expanding production of linear low density polyethylene (Rybak et al., 2008; Nguyen et al., 2010).

Up to date, this fatty acid, with a variety of functions, is mainly obtained from sea buckthorn (Hippophae rhamnoides L.), which contains about $43 \%$ palmitoleic acid in its total lipid but confronts the limitation of commercialization due to its very low lipid content in buckthron pulp, low yield and poor agronomic characteristics (Wu et al., 2012; Yang and Kallio, 2001). Oils from large scale planted oil crops, such as Sunflower and Jatropha, contain less than 2\% palmitoleic acid (Salas et al., 2004; Okullo et al., 2012). A number of unicellular oleaginous microalgae have been identified as sustainable sources for fatty acids production, but most of them only contains $8 \%-25 \%$ palmitoleic acid in fatty acid profiles (de Swaaf et al., 2003; Xiong et al., 2008; Wei et al., 2009; Han et al., 2012; Lang et al., 2011; Klok et al., 2014).

Fortunately, in our previous work, a filamentous oleaginous microalgae specie, Tribonema minus, with unbranched filaments composed of a single row of elongated and cylindrical cells, was identified as an alternative candidate for the production of lipid and palmitoleic acid due to its high lipid content (over 50\%) in biomass and dominated component of palmitoleic acid (about 50\%) in fatty acid profile (Wang et al., 2013; Guo et al., 2014; Wang et al., 2016a,b). In addition, the constructed autotrophic cultivation system has successfully demonstrated that $T$. minus has other advantages in easy harvest and resistance to the predation of grazers due to its filamentous feature (Wang et al., 2013). However, as mentioned before, on the views of feasibility of mass production of palmitoleic acid enriched lipid oil and economic viability, heterotrophic fermentation of $T$. minus with organic carbon source would be more encouraging.

In this study, the distinctive heterotrophic ability of T. minus was reported at first. As follows, the influences of different nutrients including the organic carbon sources, nitrogen sources and other trace elements, initial $\mathrm{pH}$ value and cultivation temperature on biomass density and lipid content were investigated, and finally an optimal heterotrophic condition for $T$. minus was obtained. Results have demonstrated great commercialized potential for producing both lipid oil and palmitoleic acid component by heterotrophic fermentation with filamentous microalgae T. minus.

\section{Materials and methods}

\subsection{Microalgae strain}

Freshwater filamentous microalgae $T$. minus was purchased from SAG culture collection, University of Gottingen, and main- tained in BG11 medium. Inoculum of microalgal cells was prepared in $250 \mathrm{~mL}$ flask with $100 \mathrm{~mL}$ BG11 medium under illumination intensity of $50 \mu \mathrm{mol}$ photons $\mathrm{m}^{-2} \mathrm{~s}^{-1}$, the orbital shaking rate was $180 \mathrm{rpm}$ and temperature was maintained at $27 \pm 1^{\circ} \mathrm{C}$.

\subsection{Experimental methods}

All the cultures were carried out in $250 \mathrm{~mL}$ flask with $100 \mathrm{~mL}$ modified BG11 medium (see Table 1). The photoautotrophy of $T$. minus was carried out as control with the illumination intensity of $50 \mu \mathrm{mol}$ photons $\mathrm{m}^{-2} \mathrm{~s}^{-1}$. The heterotrophy test was carried out in silver paper covered flask to shield the irradiance at $27 \pm 1^{\circ} \mathrm{C}$, and the heterotrophic medium was the modified BG11 medium with glucose of $10 \mathrm{~g} \mathrm{~L}^{-1}$.

Considering the importance of carbon source and nitrogen on fermentation, four organic carbon sources including glucose, sucrose, glycerol and sodium acetate and four popular used nitrogen sources including $\mathrm{NaNO}_{3}$, yeast extract, $\mathrm{NH}_{4} \mathrm{Cl}$ and urea were added into modified BG11 medium respectively to screen the optimal organic carbon source and nitrogen source. Though peptone is an appropriate nitrogen source (Wang et al., 2017), however here it was not taken into account due to its high price. The concentration of organic carbon source was $10 \mathrm{~g} \mathrm{~L}^{-1}$, and the concentration of the four nitrogen sources was $\mathrm{NaNO}_{3} 1.5 \mathrm{~g} \mathrm{~L}^{-1}$, yeast extract $2 \mathrm{~g} \mathrm{~L}^{-1}$, $\mathrm{NH}_{4} \mathrm{Cl} 0.89 \mathrm{~g} \mathrm{~L}^{-1}$ and urea $0.5 \mathrm{~g} \mathrm{~L}^{-1}$, respectively, which indicated the same nitrogen level of $0.017 \mathrm{~mol} \mathrm{~L}^{-1}$.

After determined glucose and urea as the optimal organic carbon source and nitrogen source (see Section 3.2), the influence of glucose concentration from $5 \mathrm{~g} \mathrm{~L}^{-1}$ to $80 \mathrm{~g} \mathrm{~L}^{-1}$ in modified BG11 medium (in which $2 \mathrm{~g} \mathrm{~L}^{-1}$ urea was used to take place $\mathrm{NaNO}_{3}$ ) on the heterotrophy of T. minus was investigated. Different concentrations of urea from $0 \mathrm{~g} \mathrm{~L}^{-1}$ to $2 \mathrm{~g} \mathrm{~L}^{-1}$ and other nutritional conditions such as $\mathrm{K}_{2} \mathrm{HPO}_{4}$ (from $0 \mathrm{~g} \mathrm{~L}^{-1}$ to $0.8 \mathrm{~g} \mathrm{~L}^{-1}$ ) and ammonium ferric citrate (from $0 \mathrm{mg} \mathrm{L}^{-1}$ to $48 \mathrm{mg} \mathrm{L}^{-1}$ ) were also designed to investigate the performance of heterotrophic culture under the same glucose concentration of $20 \mathrm{~g} \mathrm{~L}^{-1}$ in the medium.

Moreover, the influences of initial $\mathrm{pH}$ value $(4.0,6.0,7.9,9.0$ and $10.0)$ of medium and temperature $\left(17,22,27\right.$ and $\left.32{ }^{\circ} \mathrm{C}\right)$ on fermentation were also investigated.

\subsection{Analytical methods}

For biomass analyses, $5 \mathrm{~mL}$ (for autotrophy) or $2 \mathrm{~mL}$ (for heterotrophy) broth (V) were taken from the flasks everyday. The sample was filtered to a pre-weighted $0.45 \mu \mathrm{m} \mathrm{GF/C} \mathrm{filter} \mathrm{mem-}$ brane (Whatman, $\mathrm{DW}_{0}$ ) and washed for three times by distilled water. Then the membrane was oven dried at $105{ }^{\circ} \mathrm{C}$ overnight and weighted $\left(\mathrm{DW}_{1}\right)$. The dry weight (DW) was calculated as $\left(\mathrm{DW}_{1}-\mathrm{DW}_{0}\right) / \mathrm{V}$ (Wang et al., 2013).

Total lipid content was determined by gravimetric analysis according to Chen et al. (2012) with some modifications. Approximately $50 \mathrm{mg}$ of dried microalgal cells were extracted with methanol-chloroform $(2: 1, \mathrm{v} / \mathrm{v})$ after grinding and then separated into chloroform and aqueous methanol layers by adding chloro-

Table 1

Composition of modified BG11 medium.

\begin{tabular}{llll}
\hline Modified BG11 medium & & & \\
\hline $\mathrm{NaNO}_{3}$ & $1500 \mathrm{mg} \mathrm{L}^{-1}$ & $\mathrm{ZnSO}_{4} \cdot 7 \mathrm{H}_{2} \mathrm{O}$ & $0.222 \mathrm{mg} \mathrm{L}^{-1}$ \\
$\mathrm{~K}_{2} \mathrm{HPO}_{4}$ & $400 \mathrm{mg} \mathrm{L}^{-1}$ & $\mathrm{CuSO}_{4} \cdot 5 \mathrm{H}_{2} \mathrm{O}$ & $0.079 \mathrm{mg} \mathrm{L}^{-1}$ \\
$\mathrm{MgSO}_{4} \cdot 7 \mathrm{H}_{2} \mathrm{O}$ & $375 \mathrm{mg} \mathrm{L}^{-1}$ & $\mathrm{MnCl}_{2} \cdot 4 \mathrm{H}_{2} \mathrm{O}$ & $1.81 \mathrm{mg} \mathrm{L}^{-1}$ \\
$\mathrm{CaCl}_{2} \cdot 2 \mathrm{H}_{2} \mathrm{O}$ & $180 \mathrm{mg} \mathrm{L}^{-1}$ & $\mathrm{Na}_{2} \mathrm{MoO}_{4} \cdot 2 \mathrm{H}_{2} \mathrm{O}$ & $0.39 \mathrm{mg} \mathrm{L}^{-1}$ \\
$\mathrm{Na}_{2} \mathrm{CO}_{3}$ & $100 \mathrm{mg} \mathrm{L}^{-1}$ & $\mathrm{Co}\left(\mathrm{NO}_{3}\right)_{4} \cdot 6 \mathrm{H}_{2} \mathrm{O}$ & $0.0494 \mathrm{mg} \mathrm{L}^{-1}$ \\
$\mathrm{Citric}$ acid & $30 \mathrm{mg} \mathrm{L}^{-1}$ & $\mathrm{H}_{3} \mathrm{BO}_{3}$ & $2.86 \mathrm{mg} \mathrm{L}^{-1}$ \\
Ammonium ferric citrate & $24 \mathrm{mg} \mathrm{L}^{-1}$ & $\mathrm{Na}_{2} \mathrm{EDTA}$ & $5 \mathrm{mg} \mathrm{L}^{-1}$ \\
\hline
\end{tabular}


form and $1 \% \mathrm{NaCl}$ solution to make a final volume ratio of chloroform: methanol: $1 \% \mathrm{NaCl}$ of $1: 1: 0.9$. The chloroform layer was evaporated to dryness by nitrogen-blowing, and the lipid content was then calculated gravimetrically.

Fatty acid profiles were determined post-conversion to fatty acid methyl esters (FAMEs) and analyzed on a Varian 450GC (Varian Inc., USA). Lipid, together with nonadecanoic acid (C19:0) added as an internal standard, was converted to FAMEs with sulfu$\mathrm{ric}$ acid/methanol $(1: 50, \mathrm{w} / \mathrm{v})$ and incubated at $85^{\circ} \mathrm{C}$ for $2.5 \mathrm{~h}$. Nitrogen was used as carrier gas during FAMEs analysis on 450GC, and the injector temperature was set at $280^{\circ} \mathrm{C}$ with an injection volume of $2 \mu \mathrm{L}$ under split mode of 10:1. The individual FAMEs were identified by chromatographic comparison with authentic standards (Sigma) and calculated by the way reported by Chen et al. (2012).

For glucose concentration analyses, samples taken from the flasks were filtered by $0.45 \mu \mathrm{m}$ filter membrane, and the filtrate was collected to detect the glucose concentration by using a biosensor (SBA-40D, China). Glucose-biomass conversion efficiency, namely the cell growth yield on glucose, was calculated as $\left(B_{1}-B_{0}\right) /\left(G_{0}-G_{1}\right)$, where $B_{0}$ and $G_{0}$ were the initial biomass and glucose concentration, and $B_{1}$ and $G_{1}$ were the final biomass and glucose concentration, respectively.

\subsection{Statistical analysis}

All the experiments were performed in parallel triplicates and repeated twice for validation, and data was denoted as mean valu$\mathrm{e} \pm \mathrm{SE}$ ( standard error). One-way analysis of variance (ANOVA) was used to evaluate the difference of biomass and lipid content among the treatments at confidence level of 0.05 .

\section{Results and discussions}

\subsection{Identification of heterotrophic ability of T. minus}

The comparison of T. minus biomass in photoautotrophy and heterotrophy with $10 \mathrm{~g} \mathrm{~L}^{-1}$ glucose was presented in Fig. $1 \mathrm{~A}$. It showed that $T$. minus grow very fast by heterotrophy, and the biomass density reached $6.14 \mathrm{~g} \mathrm{~L}^{-1}$ at day 4 , while the biomass density was only $2 \mathrm{~g} \mathrm{~L}^{-1}$ at day 5 and $2.5 \mathrm{~g} \mathrm{~L}^{-1}$ at day 6 via photoautotrophy. It demonstrated that $T$. minus could use glucose as carbon substrate for fast heterotrophic growth. After 4 days fermentation, the glucose concentration in medium was decreased from $10 \mathrm{~g} \mathrm{~L}^{-1}$ to $0 \mathrm{~g} \mathrm{~L}^{-1}$, corresponding to the carbon/biomass conversion rate of $0.56 \mathrm{~g} \mathrm{~g}^{-1}$. The changes of lipid content by autotrophy and heterotrophy were plotted in Fig. 1B. With the prolong of the cultivation, the lipid content of biomass by autotrophy gradually increased from $25 \%$ in inoculum to about $37.9 \%$ at day 6 , while the lipid content of biomass by heterotrophy decreased to $10 \%$ at day 2 and then gradually increased to only about $18.8 \%$, much lower than that by autotrophy. Low lipid content was also observed in C. protothecoides when heterotrophic cultivation was employed (Wei et al., 2009; Li et al., 2013, 2015). A possible reason for this phenomenon might be that the major products of biosynthesis are structural substances e.g., polysaccharides and proteins for microalgae cell construction, rather than the energy storage chemicals such as lipids in the rapid growth phase of heterotrophy with glucose. In spite of this, the lipid productivity was improved to about $200 \mathrm{mg} \mathrm{L}^{-1} \mathrm{~d}^{-1}$ by heterotrophy compared with $158 \mathrm{mg} \mathrm{L}^{-1} \mathrm{~d}^{-1}$ by phototrophy. It should be noted that there was still a lot of room to improve the biomass growth rate and lipid content if an optimized heterotrophic condition such as controlled $\mathrm{C} / \mathrm{N}$ ratio of medium (Wei et al., 2009) or further lipid induction strategy was adopted.
Fatty acid profiles of $T$. minus of the both autotrophy and heterotrophy at day 6 were determined and displayed in Table 2 . In contrast to the difference on biomass density and lipid content, scarcely differences were observed in fatty acid profiles between phototrophic and heterotrophic cultures. There is insignificant difference of palmitoleic acid content for both the biomass by autotrophy and heterotrophy and palmitoleic acid is the dominated fatty acid, constituting up to $50 \%$. While oleic acid, which was usually in majority in most green algae (Griffiths et al., 2011), was only 3.0\%-3.4\% in T. minus. The second main composition of the lipid of the two cultures of $T$. minus was palmitic acid (16:0), taking a proportion of $28.0 \%-28.4 \%$, and as for the rest components, proportions were slight and inappreciable. In conclusion, analysis results revealed that heterotrophic growth of $T$. minus with glucose kept the excellent performance of producing palmitoleic acid, as the phototrophic growth exhibited.

In recent years, heterotrophic fermentation of microalgae has been paid much attention in order to solve the problem of fast production of biomass. However all the reported microalgae species which could be efficiently fermented with glucose are limited to only a few unicellular microalgae species, of which Chlorella sp. are the most used (Xiong et al., 2008; Han et al., 2012; Li et al., 2015; Perez-Garcia et al., 2011). This reported T. minus is the first one of filamentous microalgae specie. And due to the functional usage of palmitoleic acid as healthcare product, the identification of heterotrophic growth ability of filamentous oleaginous T. minus is very likely to lead a profitable bio-refinery technology for both rare omega-7 fatty acid and biodiesel production.

\subsection{Screening of organic carbon source and nitrogen source}

Different organic carbon sources and nitrogenous substances were used to evaluate the optimum carbon and nitrogen sources for heterotrophic growth of T. minus (Fig. 2). From the results shown in Fig. 2A, glycerol and sodium acetate had a slight but of no worth promotion on $T$. minus growth, and sucrose could barely offer any biomass accumulation, as well as xylose, galactose, mannose, L-rhamnose, maltose and starch investigated in this study but not shown here. Zhang et al. (2016) reported that sodium acetate could be utilized as organic carbon source for Haematococcus pluvialis heterotrophy. Sucrose is another optional organic carbon substrate for microalgae heterotrophy, but it needs to be hydrolyzed prior to use (Wang et al., 2016c). Comparably, glucose is the most commonly used organic carbon source for heterotrophic fermentation of microalgae because of its excellent performance, cheap and easy to get compared to any other substrates (PerezGarcia et al., 2011). The efficient use of glucose by T. minus for heterotrophy provides the feasibility of fermentation in industrial scale.

Nitrates were usually employed as nitrogen source for microalgae phototrophy while other nitrogenous substances such as yeast extracts and urea were preferable in heterotrophic culture of microalgae (Xiong et al., 2008; Li et al., 2015). The heterotrophic growth of T. minus with four types of nitrogen sources at the same nitrogen level in medium was presented in Fig. 2B. There was a significant influence of the nitrogen source on $T$. minus heterotrophic growth while different nitrogen sources were employed. Except ammonium chloride, $T$. minus had a well growth with the three other nitrogen sources. Especially for the urea, the biomass density was observed about $7.1 \mathrm{~g} \mathrm{~L}^{-1}$ in only 2 days cultivation, which was much higher than that of sodium nitrate and yeast extract $(p<0.05)$. There were little differences among the lipid contents of $T$. minus with various nitrogen sources except ammonium chloride (Fig. 2C). With ammonium chloride as nitrogen source, the lipid content increased to about $34.2 \%$ of dry weight after 6 days fermentation, which was higher than that of sodium nitrate 

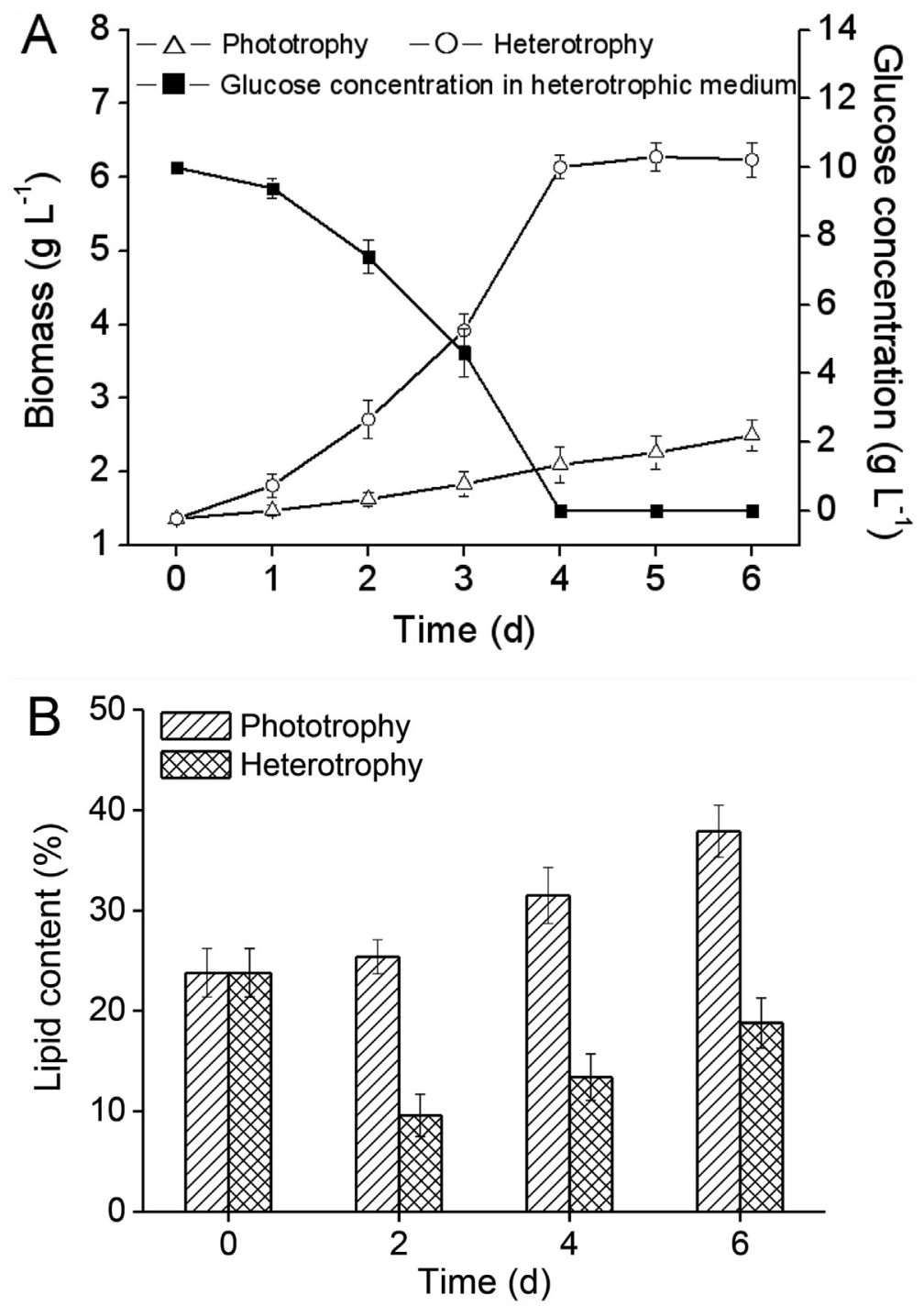

Fig. 1. Growth (A) and lipid accumulation (B) of T. minus under phototrophic and heterotrophic culture conditions.

Table 2

Fatty acid profiles of T. minus under photoautotrophic and heterotrophic culture conditions.

\begin{tabular}{lll}
\hline Fatty acid composition & Photoautotrophy & Heterotrophy \\
\hline $14: 0$ & 6.9 & 8.7 \\
$16: 0$ & 28.4 & 28.0 \\
$16: 1$ & 50.7 & 50.1 \\
$18: 0$ & 1.0 & 1.7 \\
$18: 1$ & 3.0 & 3.4 \\
$18: 2$ & 1.0 & 0.3 \\
$20: 4$ & 3.0 & 2.4 \\
$20: 5$ & 3.0 & 2.8 \\
Others & 3.0 & 2.6 \\
\hline
\end{tabular}

( $18.8 \%$ of DW), yeast extract ( $25.5 \%$ of DW) and urea ( $20.4 \%$ of DW). However as shown in Fig. 2B, its biomass density was much lower than the other nitrogen sources, so its lipid productivity was very poor. The reason may be attributed to the serious inhibition or stress of ammonium nitrogen by ammonium chloride on algal cell. The lipid productivity reached the highest of $255 \mathrm{mg} \mathrm{L}^{-1} \mathrm{~d}^{-1}$ when urea was used as nitrogen source, indicating that urea was the most appropriate nitrogen source for heterotrophic culture of $T$. minus.

\subsection{Influence of medium nutrient composition on T. minus} heterotrophy

The influences of medium nutrient composition including glucose, urea, $\mathrm{K}_{2} \mathrm{HPO}_{4}$ and ammonium ferric citrate on heterotrophic growth of $T$. minus were investigated and the results were shown in Fig. 3. With the increase of glucose concentration from $5 \mathrm{~g} \mathrm{~L}^{-1}$ to $80 \mathrm{~g} \mathrm{~L}^{-1}$, the final biomass density at day 6 were $4.9 \mathrm{~g} \mathrm{~L}^{-1}$, $9.9 \mathrm{~g} \mathrm{~L}^{-1}, 19.9 \mathrm{~g} \mathrm{~L}^{-1}, 25.6 \mathrm{~g} \mathrm{~L}^{-1}$ and $30.8 \mathrm{~g} \mathrm{~L}^{-1}$ respectively (Fig. 3A). The changes of residual glucose concentration in medium were shown in Fig. 3B. With extension of fermentation, glucose was consumed for the construction of $T$. minus cells. Comparing Fig. $3 \mathrm{~A}$ and $\mathrm{B}$, when the initial glucose concentration was 5,10 , 20 and $40 \mathrm{~g} \mathrm{~L}^{-1}$, all the glucose was exhausted at day 2, day 3, day 4 and day 5 , respectively, at which the biomass density reached the highest. However, with initial concentration of $80 \mathrm{~g} \mathrm{~L}^{-1}$ glucose, the highest biomass density of $30.8 \mathrm{~g} \mathrm{~L}^{-1}$ was reached at day 5 while $37 \mathrm{~g} \mathrm{~L}^{-1}$ glucose was residual. Glucosebiomass conversion efficiency, namely the cell growth yield on glucose, is one of important technical indicators for fermentation. For the five initial glucose concentration gradients, the glucosebiomass conversion efficiency was calculated as $0.66,0.73,0.87$,

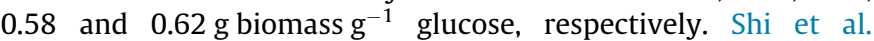



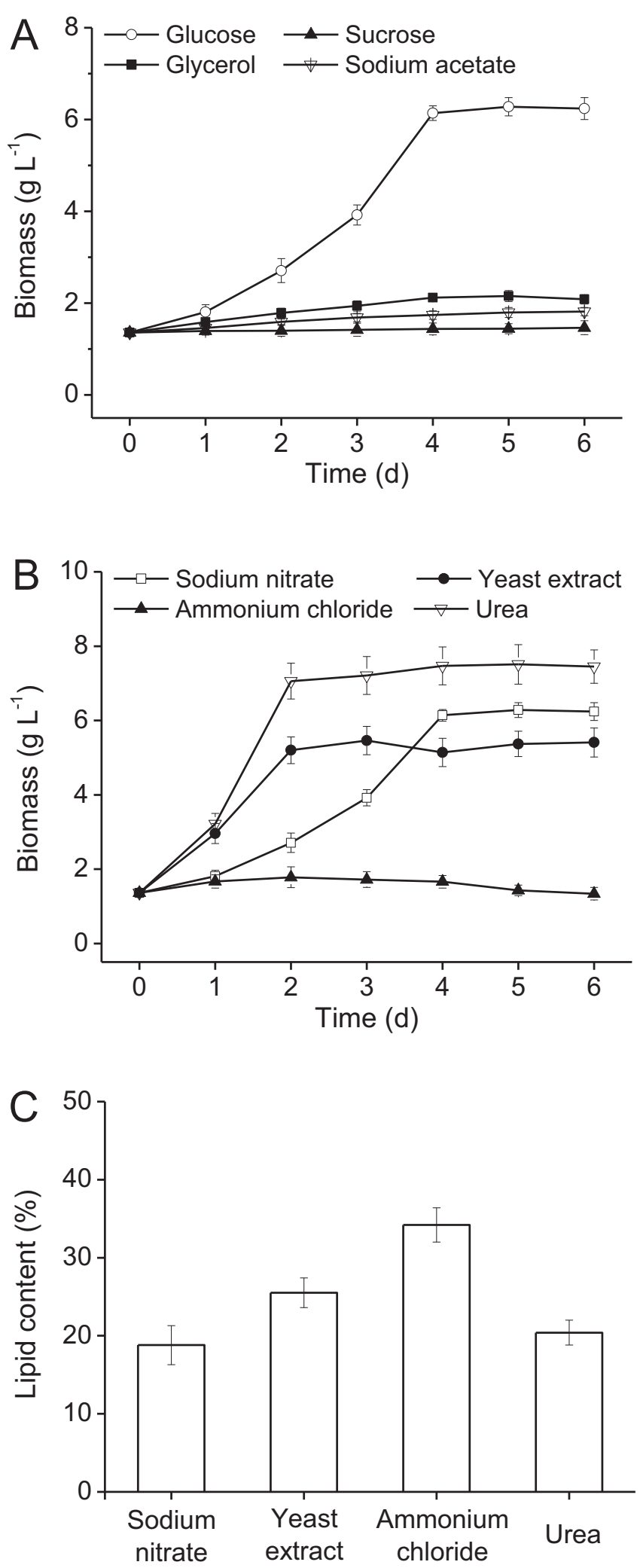

Fig. 2. Heterotrophic growth of T. minus with different carbon sources (A) and nitrogen sources (B), and lipid accumulation (C) of $T$. minus with different nitrogen sources.

(1999) reported that, in heterotrophic culture of $C$. protothecoides CS-41, the maximum biomass increased from $4.9 \mathrm{~g} \mathrm{~L}^{-1}$ to $31.2 \mathrm{~g} \mathrm{~L}^{-1}$ with an increase in initial glucose concentration from $10 \mathrm{~g} \mathrm{~L}^{-1}$ to $80 \mathrm{~g} \mathrm{~L}^{-1}$, which was similar to this work. However, the glucose-biomass conversion efficiency of $C$. protothecoides was only $0.39-0.46 \mathrm{~g} \mathrm{~g}^{-1}$, which was much lower than that of $T$. minus. Another research released by Jiang and Chen (2000) revealed that $C$. cohnii could also grow well heterotrophically over a range of glucose concentrations $\left(5-40 \mathrm{~g} \mathrm{~L}^{-1}\right)$ and obtained a growth yield on glucose of $0.6 \mathrm{~g} \mathrm{~g}^{-1}$ at initial glucose concentration of $20 \mathrm{~g} \mathrm{~L}^{-1}$ in medium. Anyway, appropriate lower initial glucose concentration, such as $20 \mathrm{~g} \mathrm{~L}^{-1}$ would be better on the view of substrate utilization efficiency.

The biomass production was significantly improved when the concentration of urea was increased from 0 to $0.25 \mathrm{~g} \mathrm{~L}^{-1}$ (Fig. 3C) $(p<0.05)$. By further addition of urea, the fermentation was dramatically facilitated, for instance, the culture time to reach the highest biomass density was shortened to only 3 days when the urea concentration was $2 \mathrm{~g} \mathrm{~L}^{-1}$, which was half of that when the urea concentration was $0.5 \mathrm{~g} \mathrm{~L}^{-1}$. As for $\mathrm{K}_{2} \mathrm{HPO}_{4}$ and ammonium ferric citrate, the analogous effect on heterotrophic growth of $T$. minus was observed and shown in Fig. 3D and E, respectively. Both of the growth and final biomass density were enhanced by increasing $\mathrm{K}_{2} \mathrm{HPO}_{4}$ and ammonium ferric citrate concentrations, but it should be noted that excess nutrients may induce no more facilitation and cause the nutrients costly for heterotrophic growth of $T$. minus.

The lipid contents of heterotrophic T. minus under different nutrients concentrations were determined and presented in Fig. 3F, which revealed diverse effects among different nutrients and different concentrations on lipid content. High glucose concentrations were conducive to the accumulation of lipid, while the lower groups leaded to a significant reduction of lipid content, which could be speculated as the result of carbon insufficiency after rapid growth. On the contrary, the deprivation of nitrogen resulted in a promotion of lipid accumulation. Such phenomenon has been widely validated by most reports of microalgae by both autotrophy and heterotrophy. For example, under the nitrogen starvation, the productivity of fatty acids of heterotrophic C. vulgaris was determined as three times greater than that under nitrogen sufficient conditions (Shen et al., 2016). However, for this T. minus, in our previous work of $T$. minus autotrophy, nitrogen starvation resulted in lower lipid content (Guo et al., 2014). The opposite effect of nitrogen starvation on lipid accumulation between phototrophic and heterotrophic cultivation methods could be a complicated process, and yet it needs to be further studied intensively. Except the free $\mathrm{K}_{2} \mathrm{HPO}_{4}$ experiment, the lipid content was observed a little increase when the concentration of $\mathrm{K}_{2} \mathrm{HPO}_{4}$ in medium increased from $0.05 \mathrm{~g} \mathrm{~L}^{-1}$ to $0.8 \mathrm{~g} \mathrm{~L}^{-1}$. The concentration of ammonium ferric citrate seems have insignificant influence on the lipid content.

Overall, the lipid content of heterotrophic T. minus under various nutrients conditions was only in the range from $11 \%$ to $31 \%$, which was much lower than that of phototrophic culture, 50$60 \%$ (Wang et al., 2013), but considering the biomass density, the highest lipid productivity obtained under the condition of $80 \mathrm{~g} \mathrm{~L}^{-1}$ glucose was $730 \mathrm{mg} \mathrm{L}^{-1} \mathrm{~d}^{-1}$, which is almost 5 folds compared with autotrophy, indicating heterotrophy could enormously improve the efficiency of lipid production. If further optimization such as $\mathrm{C} / \mathrm{N}$ controlling and fed-batch were adopted, the potential of heterotrophy for lipid production is worth looking forward to.

\subsection{Effect of $\mathrm{pH}$ and temperature influence on T. minus heterotrophy}

Effects of initial $\mathrm{pH}$ value of medium on heterotrophic growth of T. minus were evaluated and shown in Fig. 4A. It shown that mild $\mathrm{pH}$ environments ranged from 6 to 9 was adaptive for heterotrophy of $T$. minus, but at weakly alkaline, there was a little longer of the lag phase $(p<0.05)$.While the final algal density and lipid content at $\mathrm{pH} 6.0$ and 7.9 approached the same level after three days fermentation, it indicated that the medium close to neutral had 

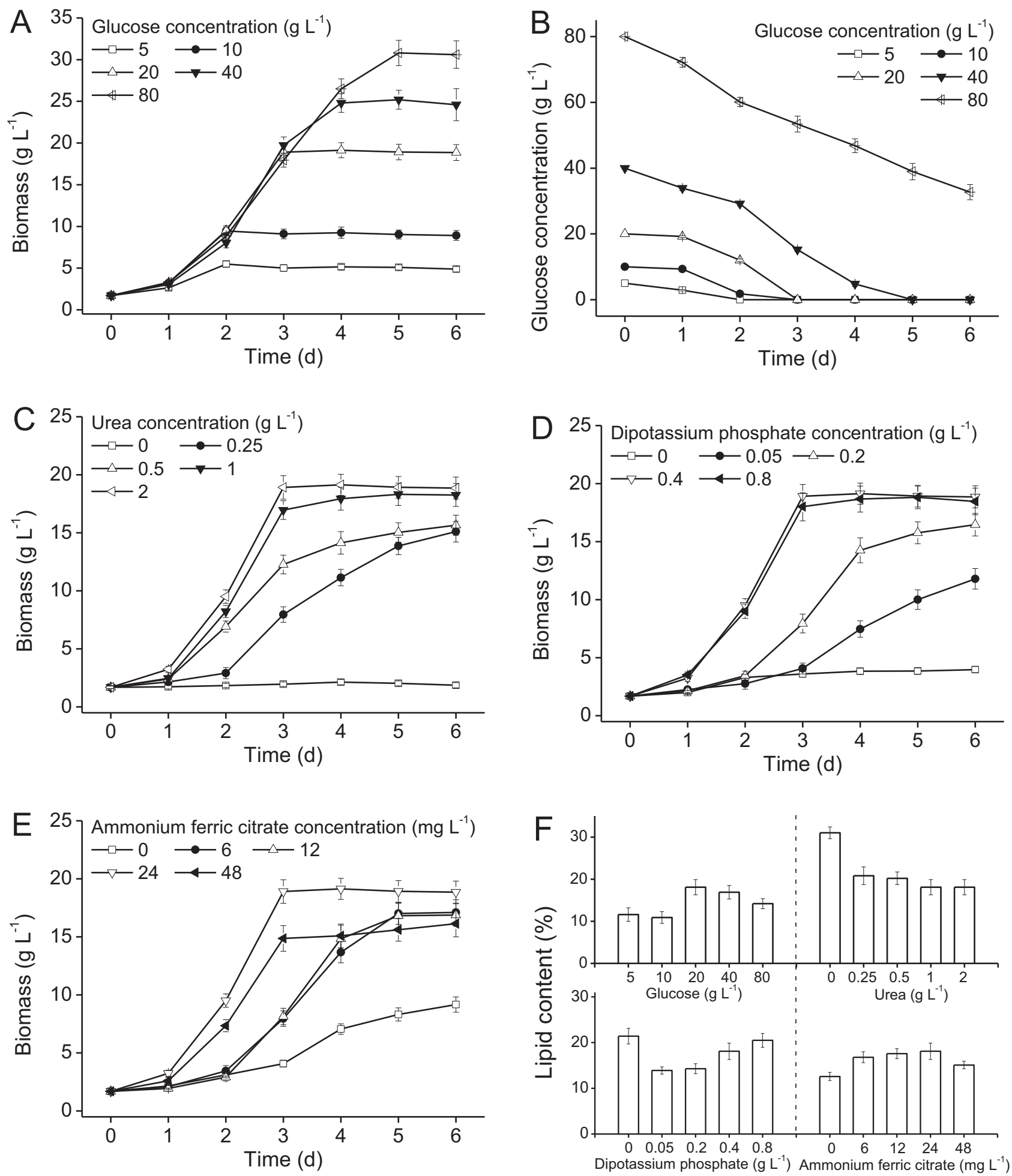

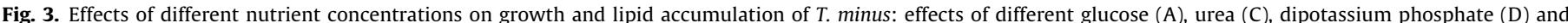

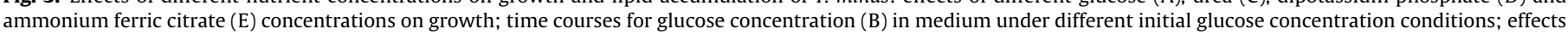
of different nutrient concentrations on lipid accumulation (F).

insignificant influence on fermentation. However the heterotrophic growth was seriously inhibited when the initial $\mathrm{pH}$ value was too high to 10.0 or too low to 4.0 ( $p<0.05$ ). Results from Shi et al. (2006), Jiang and Chen (2000) also suggested that the $\mathrm{pH}$ values of 6.0 and 7.2, a closely neutral condition of medium, were optimal for heterotrophic culture of $C$. protothecoides and $C$. cohnii respectively in order to obtain the highest biomass. A slight rise of lipid content when initial $\mathrm{pH}$ of medium was increased from 7.9 to 10.0 is reasonably contributed to the alkaline stress.

The effect of temperature on T.minus heterotrophic growth was shown in Fig. 4B., the growth of $T$. minus was notably expedited when the temperature was raised from $17^{\circ} \mathrm{C}$ to $27^{\circ} \mathrm{C}$, and the culture time to reach the highest biomass was shortened by 2 days (Fig. 4B) ( $p<0.05)$. Shi et al. (2006) investigated the heterotrophic 

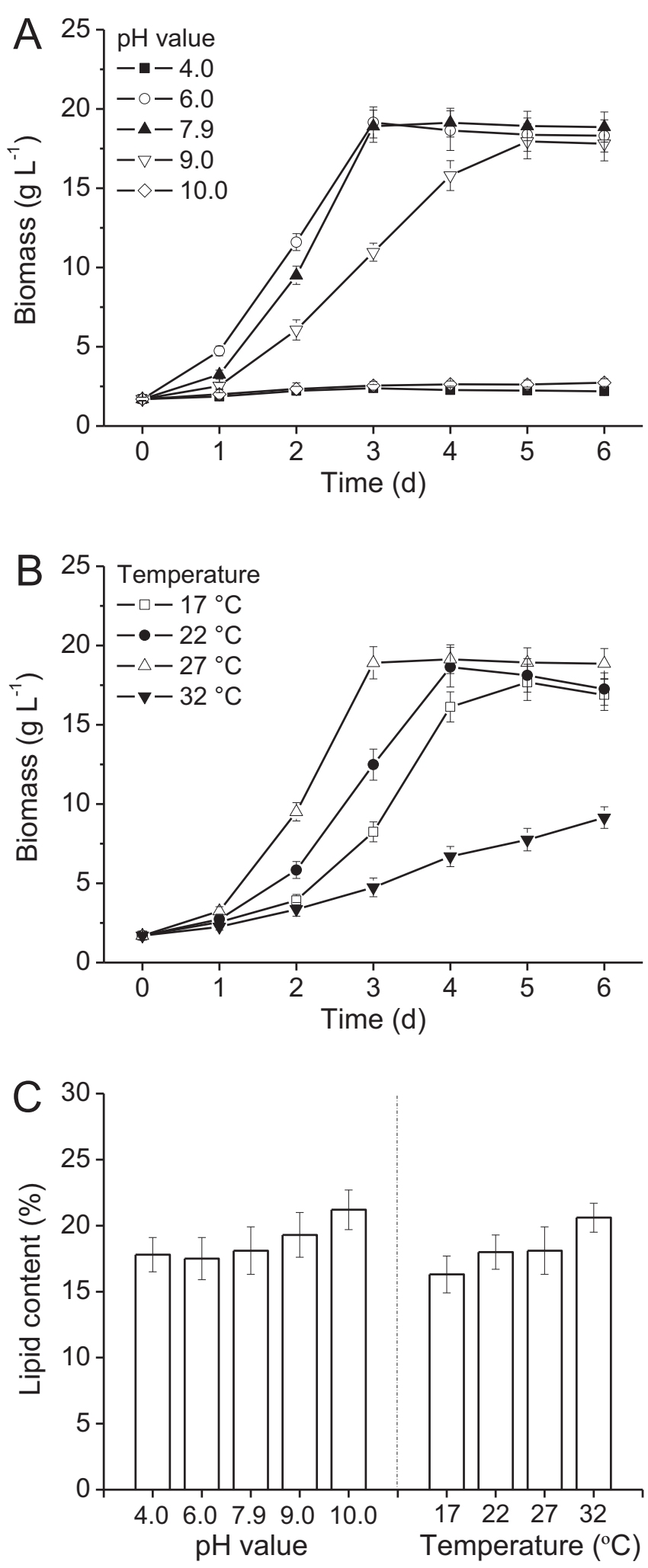

Fig. 4. Effects of different culture conditions on growth and lipid accumulation of $T$. minus: effects of initial $\mathrm{pH}$ value (A) and temperature (B) on growth; effects of different culture conditions on lipid accumulation (C).

growth of Chlorella and suggested $28^{\circ} \mathrm{C}$ around was the most appropriate temperature. There was, whereas, a dramatic reduction of growth rate when the fermentation temperature was raised to $32{ }^{\circ} \mathrm{C}$. This temperature region has a little difference to that by autotrophy. Wang et al. (2016b) reported that T. minus showed an increasing promotion in biomass by the raising of temperature from $5{ }^{\circ} \mathrm{C}$ to $35^{\circ} \mathrm{C}$. A possible reason for this was that the activity of enzymes, especially those related to glucose metabolism, was restrained by the high temperature in heterotrophic conditions.

Inconspicuous differences were observed in lipid content between different conditions of $\mathrm{pH}$ value and temperature (Fig. 4C), it indicated that both high $\mathrm{pH}$ value and high temperature were slightly beneficial to the lipid accumulation of heterotrophic T. minus, but resulted in a reduction in lipid productivity due to their inhibition on growth. It seemed that in the long run, twostep fermentation strategy, that is, appropriate low $\mathrm{pH}$ value to 6.0 and temperature to $27^{\circ} \mathrm{C}$ for biomass fast growth in first step and then a little higher $\mathrm{pH}$ value to 10.0 and temperature to $32{ }^{\circ} \mathrm{C}$ for the promotion of lipid accumulation in the second step, may be an effective option of $T$. minus heterotrophy for lipid and palmitoleic acid production.

\section{Conclusions}

This work first reported the ability of heterotrophy of T. minus with glucose. Glucose and urea were the most appropriate carbon and nitrogen source to boost the fermentation. Highest biomass and lipid productivity of $30.8 \mathrm{~g} \mathrm{~L}^{-1}$ and $730 \mathrm{mg} \mathrm{L}^{-1} \mathrm{~d}^{-1}$ were obtained by adding $80 \mathrm{~g} \mathrm{~L}^{-1}$ glucose at once while the highest glucose-biomass conversion efficiency of $0.87 \mathrm{~g} \mathrm{~g}^{-1}$ was obtained at initial glucose concentration of $20 \mathrm{~g} \mathrm{~L}^{-1}$. Culture conditions for heterotrophy of $T$. minus were optimized. Results provided a promising way of heterotrophic fermentation with $T$. minus for biomass and lipid, especially palmitoleic acid production.

\section{Acknowledgements}

This work was financially supported by Marine economic innovation and development regional demonstration project of Qingdao and Research Program of Application Foundation of Qingdao (Grant No. 16-5-1-68-jch) from Qingdao Science.

\section{References}

Becker, E., 2007. Micro-algae as a source of protein. Biotechnol. Adv. 25, 207-210. Brennan, L., Owende, P., 2010. Biofuels from microalgae-a review of technologies for production, processing, and extractions of biofuels and co-products. Renewable Sustainable Energy Rev. 14, 557-577.

Cao, Y.J., Liu, W., Xu, X., Zhang, H.B., Wang, J.M., Xian, M., 2014. Production of free monounsaturated fatty acids by metabolically engineered Escherichia coli. Biotechnol. Biofuels 7, 59-69.

Chen, L., Liu, T.Z., Zhang, W., Chen, X.L., Wang, J.F., 2012. Biodiesel production from algae oil high in free fatty acids by two-step catalytic conversion. Bioresour. Technol. 111, 208-214.

de Swaaf, M., Sijtsma, L., Pronk, J., 2003. High-cell-density fed-batch cultivation of the docosahexaenoic acid producing marine alga Crypthecodinium cohnii. Biotechnol. Bioeng. 81, 666-672.

Griffiths, M.J., Harrison, S.T.L., 2009. Lipid productivity as a key characteristic for choosing algal species for biodiesel production. J. Appl. Phycol. 21, 493-507.

Griffiths, M.J., Hiller, R.P., Harrison, S.T.L., 2011. Lipid productivity, settling potential and fatty acid profile of 11 microalgal species grown under nitrogen replete and limited conditions. J. Appl. Phycol. 24, 989-1001.

Guo, F.J., Wang, H., Wang, J.F., Zhou, W.J., Gao, L.L., Chen, L., Dong, Q.Z., Zhang, W. Liu, T.Z., 2014. Special biochemical responses to nitrogen deprivation of filamentous oleaginous microalgae Tribonema sp. Bioresour. Technol. 158, 1924.

Han, F.F., Huang, J.K., Li, Y.G., Wang, W.L., Wang, J., Fan, J.H., Shen, G.M., 2012 Enhancement of microalgal biomass and lipid productivities by a model of photoautotrophic culture with heterotrophic cells as seed. Bioresour. Technol. 118, 431-437.

Harun, R., Singh, M., Forde, G.M., Danquah, M.K., 2010. Bioprocess engineering of microalgae to produce a variety of consumer products. Renewable Sustainable Energy Rev. 14, 1037-1047.

Jiang, Y., Chen, F., 2000. Effects of medium glucose concentration and $\mathrm{pH}$ on docosahexaenoic acid content of heterotrophic Crypthecodinium cohnii. Process Biochem. 35, 1205-1209. 
Klok, A.J., Lamers, P.P., Martens, D.E., Draaisma, R.B., Wijffels, R.H., 2014. Edible oils from microalgae: insights in TAG accumulation. Trends Biotechnol. 32, 521528.

Knothe, G., 2010. Biodiesel derived from a model oil enriched in palmitoleic acid, macadamia nut oil. Energy Fuels 24, 2098-2103.

Lang, I.K., Hodac, L., Friedl, T., Feussner, I., 2011. Fatty acid profiles and their distribution patterns in microalgae: a comprehensive analysis of more than 2000 strains from the SAG culture collection. BMC Plant Biol. 11, 124-140.

Li, Y.Q., Mu, J.X., Chen, D., Han, F.X., Xu, H., Kong, F., Xie, F., Feng, B., 2013. Production of biomass and lipid by the microalgae Chlorella protothecoides with heterotrophic-Cu(II) stressed (HCUS) coupling cultivation. Bioresour. Technol. $148,283-292$.

Li, Y.Q., Mu, J.X., Chen, D., Xu, H., Han, F.X., 2015. Enhanced lipid accumulation and biodiesel production by oleaginous Chlorella protothecoides under a structured heterotrophic-iron (II) induction strategy. World J. Microbiol. Biotechnol. 31, 773-783.

Maedler, K., Oberholzer, J., Bucher, P., Spinas, G.A., Donath, M.Y., 2003. Monounsaturated fatty acids prevent the deleterious effects of palmitate and high glucose on human pancreatic beta-cell turnover and function. Diabetes 52, 726-733.

Mozaffarian, D., Cao, H., King, I.B., Rozenn, N.L., Song, X.L., Siscovick, D.S. Hotamisligil, C.S., 2010. Circulating palmitoleic acid and risk of metabolic abnormalities and new-onset diabetes. Am. J. Clin. Nutr. 92, 1350-1358.

Nguyen, H.T., Mishra, G., Whittle, E., Pidowich, M.S., Bevan, S.A., Merlo, A.O., Walsh, T.A., Shanklin, J., 2010. Metabolic engineering of seeds can achieve levels of omega-7 fatty acids comparable to the highest levels found in natural plant sources. Plant Physiol. 154, 1897-1904.

Okullo, A.A., Temu, A.K., Ogwok, P., Ntalikwa, J.W., 2012. Physico-chemica properties of biodiesel from jatropha and castor oils. Int. J. Renewable Energy Res. 2, 47-52.

Perez-Garcia, O., Escalante, F.M.E., de-Bashan, L.E., Bashan, Y., 2011. Heterotrophic cultures of microalgae: metabolism and potential products. Water Res. 45, 11 36.

Pienkos, P.T., Darzins, A., 2009. The promise and challenges of microalgal-derived biofuels. Biofuel Bioprod. Biorefin. 3, 431-440.

Rodolfi, L., Zittelli, G.C., Bassi, N., Padovani, G., Biondi, N., Bonini, G., Tredici, M.R. 2009. Microalgae for oil: strain selection, induction of lipid synthesis and outdoor mass cultivation in a low-cost photobioreactor. Biotechnol. Bioeng. $102,100-112$.

Rybak, A., Fokou, P.A., Meier, M.A.R., 2008. Metathesis as a versatile tool in oleochemistry. Eur. J. Lipid Sci. Technol. 110, 797-804.

Salas, J.J., Martinez-Force, E., Garces, R., 2004. Biochemical characterization of a high palmitoleic acid Helianthus annuus mutant. Plant Physiol. Biochem. 42, 373381.

Shen, X.F., Liu, J.J., Chauhan, A.S., Hu, H., Ma, L.L., Lam, P.K.S., Zeng, R.J., 2016. Combining nitrogen starvation with sufficient phosphorus supply for enhanced biodiesel productivity of Chlorella vulgaris fed on acetate. Algal Res. 17, $261-$ 267.

Shi, X.M., Liu, H.J., Zhang, X.W., Chen, F., 1999. Production of biomass and lutein by Chlorella protothecoides at various glucose concentrations in heterotrophic cultures. Process Biochem. 34, 341-347.
Shi, X.M., Wu, Z.Y., Chen, F., 2006. Kinetic modeling of lutein production by heterotrophic Chlorella at various pH and temperatures. Mol. Nutr. Food Res. 50, 763-768.

Singh, J., Gu, S., 2010. Commercialization potential of microalgae for biofuels production. Renewable Sustainable Energy Rev. 14, 2596-2610.

Spolaore, P., Joannis-Cassan, C., Duran, E., Isambert, A., 2006. Commercial applications of microalgae. J. Biosci. Bioeng. 101, 87-96.

Stefan, N., Kantartzis, K., Celebi, N., Staiger, H., Machann, J., Schick, F., 2010. Circulating palmitoleate strongly and independently predicts insulin sensitivity in humans. Diabetes Care 33, 405-407.

Wang, H., Gao, L.L., Chen, L., Guo, F.J., Liu, T.Z., 2013. Integration process of biodiesel production from filamentous oleaginous microalgae Tribonema minus. Bioresour. Technol. 142, 39-44.

Wang, H., Zhou, W.J., Cheng, W.T., Gao, L.L., Liu, T.Z., 2016a. Strategy study on enhancing lipid productivity of filamentous oleaginous microalgae Tribonema. Bioresour. Technol. 218, 161-166.

Wang, H., Gao, L.L., Zhou, W.J., Liu, T.Z., 2016b. Growth and palmitoleic acid accumulation of filamentous oleaginous microalgae Tribonema minus at varying temperatures and light regimes. Bioprocess Biosyst. Eng. 39, 1589-1595.

Wang, S.K., Wu, Y., Wang, X., 2016c. Heterotrophic cultivation of Chlorella pyrenoidosa using sucrose as the sole carbon source by co-culture with Rhodotorula glutinis. Bioresour. Technol. 220, 615-620.

Wang, H., Zhou, W.J., Shao, H.M., Liu, T.Z., 2017. A comparative analysis of biomass and lipid content in five Tribonema sp. strains at autotrophic, heterotrophic and mixotrophic cultivation. Algal Res. 24, 284-289.

Wei, A.L., Zhang, X.W. Wei, D., Chen, G., Wu, QY., Yang S.T., 2009. Effects of cassava starch hydrolysate on cell growth and lipid accumulation of the heterotrophic microalgae Chlorella protothecoides. J. Ind. Microbiol. Biotechnol. 36, 1383-1389.

Welters, H.J., Diakogiannaki, E., Mordue, J.M., Tadayyon, M., Smith, S.A., Morgan, N. G., 2006. Differential protective effects of palmitoleic acid and cAMP on caspase activation and cell viability in pancreatic beta-cells exposed to palmitate. Apoptosis 11, 1231-1238.

Wijffels, R.H., Barbosa, M.J., 2010. An outlook on microalgae biofuels. Science 329, 796-799.

Wu, Y.M., Li, R.Z., Hildebrand, D.F., 2012. Biosynthesis and metabolic engineering of palmitoleate production, an important contributor to human health and sustainable industry. Prog. Lipid Res. 51, 340-349.

Xiao, Y.B., Lu, Y., Dai, J.B., Wu, Q.Y., 2015. Industrial fermentation of Auxenochlorella protothecoides for production of biodiesel and its application in vehicle diesel engines. Front. Bioeng. Biotechnol. 3, 577-584.

Xiong, W., Li, X.F., Xiang, J.Y., Wu, Q.Y., 2008. High-density fermentation of microalga Chlorella protothecoides in bioreactor for microbio-diesel production. Appl. Microbiol. Biotechnol. 78, 29-36.

Yang, B.R., Kallio, H.P., 2001. Fatty acid composition of lipids in sea buckthorn (Hippophae rhamnoides L.) berries of different origins. J. Agric. Food Chem. 49, 1939-1947.

Zhang, Z., Wang, B.B., Hu, O. Sommerfeld, M., Li, Y.G., Han, D.X., 2016. A new paradigm for producing astaxanthin from the unicellular green alga Haematococcus pluvialis. Biotechnol. Bioeng. 113, 2088-2099. 